\title{
Seeing clearly for better health
}

\section{New directions in health care will be needed beyond this year's federal election, with a matching vision of a healthier future from both major contestants}

\section{t 2 pm on Monday, 17 June 2013, His Holiness}

the Dalai Lama arrived at Westmead Hospital in

Sydney, not as a patient (thank goodness) but as a distinguished guest. Surrounded by a swirl of 10 police escort motorcycles and four security cars worthy of President Jed Bartlet from The West Wing, His Holiness landed and then embraced, smiled at and bestowed long white silk scarves upon the members of his welcoming party.

Security men spoke into tiny microphones at their wrists, and freaked out as the Dalai Lama strode into the waiting crowds. Dozens of cameras clicked as he made his way to the overflowing John Loewenthal Auditorium for a colloquium on current ethical questions - about individual and social responsibility in a world loaded with inequality, about Indigenous health and the interface between politics and health care. In welcoming him, I remarked that I could not imagine gathering an audience of this size to discuss our budget. The audience smiled their agreement and then they listened and questioned.

No doubt the Dalai Lama has his own political agenda. But for an hour on that wintry afternoon, staff who each day commit their lives to caring for others were inspired not by his politics, not by his grasp of economics, but by the optimism he exuded, by his spirituality and goodwill, by his warm humour and canny pragmatism.

"It's the economy, stupid!" may be true and politicians forget it at their peril, but for many voters there is a desire that politicians address us also at our deepest level, honouring our sense of destiny and moral commitment. We want a vision, and we want to hear a story of our progress to date and what its next chapter might be, how things can be better in the future and how we can help. Only a positive view of the future, connected to our moral purpose and to how we want to be, will lead to effective and inclusive policy. But such a vision on its own is not enough. It will inevitably also need to take account of material, social and organisational reality.

Vision, of course, means looking forward. We do not need threatening and dire statements about how bad things are (they aren't): imagine, a friend said to me recently, the outcome if Martin Luther King had announced, "I have a nightmare!" We need a dream that guides future developments. We also need policies to turn that dream into daytime reality.

Between now and the federal election scheduled for 14 September this year, we have the opportunity to reflect on

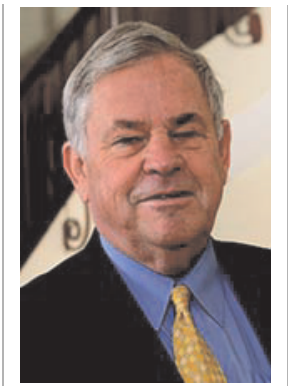

Stephen R Leeder MD, PhD, FRACP, Editor-in-Chief

Medical Journal of Australia, Sydney, NSW. sleeder@mja.com.au

doi: 10.5694/mjal3.10837

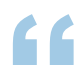

policy may not yield all the results we seek, but we can at least be clear about what we, as health care professionals, value and wish to see enhanced the health reforms of the past 4 years and consider what has been achieved, and what has not been achieved. Importantly, we need to use that discussion to know what we need to do next.

We can have a vision and plan to transform it into action and results. But policies are not neat prose or detailed architectural plans to be easily and faithfully followed. Public policy formation is a complex phenomenon, with many players and multiple agendas unfolding. As a way forward, evidence from the real world may be a more defined and stable base from which to work. For this reason, many of us yearn for more evidence-based policy. But as social scientist Brian Head argues, the idea of "evidence-based" policy can be challenged and may be an unrealistic expectation. ${ }^{1}$

Policy debate and decision making are inherently political and value-based. "Policy decisions are not deduced primarily from facts and empirical models", Head states, "but from politics, judgement and debate. Policy domains are inherently marked by the interplay of facts, norms and desired actions. Some policy settings are data-resistant owing to governmental commitments." ${ }^{1}$

Evidence-based policy is also challenged because "information is perceived and used in different ways, by actors looking through different 'lenses'. From this perspective, there is more than one type of relevant 'evidence ${ }^{\prime \prime} .{ }^{1}$ Head speaks of "three lenses" of evidence political know-how, systematic research, and professional practice. "The three-lenses approach suggests that there may be importantly divergent perspectives on whether and how to increase mutual understanding and shared objectives." 1

So policy may not yield all the results we seek, but we can at least be clear about what we, as health care professionals, value and wish to see enhanced. We can contribute. We can be at the policy table. Between now and 14 September, the Journal will publish a series of opinions by health leaders, each a page long, about the future and what we should consider in relation to health policy.

We hope that these short essays will contribute to the formation of useful policy by those who compete to lead us through the next 4 years. And may the vision be 20/20!

Competing interests: No relevant disclosures.

Provenance: Commissioned; not externally peer reviewed.

1 Head B. Three lenses of evidence-based policy. Aust J Public Admin 2008; 67: 1-11. 